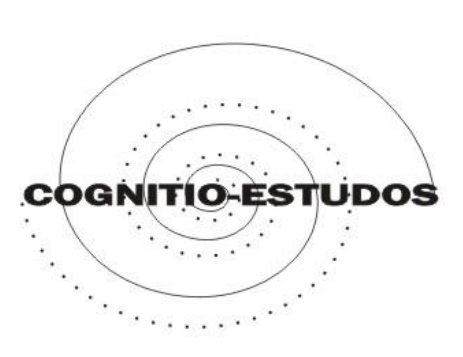

Revista Eletrônica de Filosofia

Philosophy Eletronic Journal

ISSN 1809-8428

São Paulo: Centro de Estudos de Pragmatismo

Programa de Estudos Pós-Graduados em Filosofia

Pontifícia Universidade Católica de São Paulo

Disponível em http://www.pucsp.br/pragmatismo

Vol. 16, no. 1, janeiro-junho, 2019, p.17-29

DOI: $10.23925 / 1809-8428.2019 v 16 i 1 p 17-29$

\title{
DEWEY E O PADRÃO OU ESTRUTURA DO ATO INVESTIGATIVO HUMANO
}

\author{
Caio César Cabral \\ Doutor pelo programa de Pós-Graduação em Filosofia do Departamento de Filosofia da Universidade \\ de São Paulo (USP), SP - Brasil \\ caiock@gmail.com
}

\begin{abstract}
Resumo: Dewey identifica uma estrutura comum de investigação compartilhada pelo senso comum e pela ciência, e nosso objetivo, neste artigo, é analisar esta estrutura, expondo no detalhe suas etapas constituintes. Nosso percurso pode ser assim resumido: é fato que tanto o homem da vida comum como o cientista defrontam-se com situações concretas de dúvida e obscuridade, vale dizer, com problemas concretos. Nestas situações, ambos vislumbram primeiramente uma vaga sugestão de solução, baseada nos "fatos do caso" existentes, a qual deve ser intelectualizada, ou seja, transformada numa hipótese contendo uma previsão dos resultados. Esta ideia é desenvolvida em seus significados pelo raciocínio, que identifica as consequências da ideia, ao pô-la em relação com sistemas de outras ideias formuladas previamente. A solução hipotética do problema dirige e articula a ação subsequente ou o experimento. E será precisamente o experimento a dizer se a solução proposta deve ser aceita ou rejeitada ou ainda corrigida, a fim de solucionar o problema em mãos. Em nosso itinerário, confrontaremos ainda a concepção de Dewey com a psicologia subjetivista fundamentada no pensamento de George Berkeley (1685-1753). Finalmente, traremos uma crítica de Kaufmann (1959) ao modo como Dewey concebe a relação entre a metodologia e a lógica da pesquisa humana.
\end{abstract}

Palavras-chave: Ciência. Senso comum. Investigação. John Dewey.

\section{DEWEY AND THE STANDARD OR STRUCTURE OF THE HUMAN INVESTIGATIVE ACT}

Abstract: Dewey identifies a common structure of research shared by common sense and science, and our goal in this article is to analyze this structure, exposing in detail its constituent steps. Our course can be summarized as follows: it is a fact that both the man of ordinary life and the scientist are confronted with concrete situations of doubt and obscurity, that is to say, with concrete problems. In these situations, both first glimpse a vague suggestion of solution, based on the "facts of the case", which must be intellectualized, that is, transformed into a hypothesis containing a prediction of the results. This idea is developed in its meanings by reasoning, which identifies the consequences of the idea, putting it in relation to systems of other ideas formulated previously. The hypothetical solution of the problem directs and articulates the subsequent action or experiment. And it will be precisely the experiment to say whether the proposed solution should be accepted or rejected or even corrected in order to solve the problem at hand. In our itinerary, we will also confront Dewey's conception with the psychology based on the thought of George Berkeley (1685-1753). Finally, we will bring a critique of Kaufmann (1959) to the way Dewey conceives the relationship between methodology and the logic of human research.

Keywords: Science. Common sense. Inquiry. John Dewey. 


\section{Introdução}

No âmbito do senso comum como no da ciência, o ato investigativo apresenta um padrão comum. Para Dewey, a investigação enquanto solução de problemas só pode lograr êxito, ou seja, alcançar a definição de uma situação que em princípio se mostra indefinida, observando-se cinco passos ou etapas fundamentais. Cada uma delas, como mostraremos, reforça a tese de Dewey de que a inteligência não é simples contemplação geradora de conhecimento; ela é uma operação, uma ação dirigida e refletida, e, portanto, transformadora da realidade. Neste cenário, 0 conhecimento só pode ser entendido como o resultado da pesquisa, uma vez que esta sempre se dá em conformidade com objetivos práticos. Mostraremos, nas páginas seguintes, que as etapas constituintes do ato investigativo são, segundo Dewey, os meios mais eficazes (os únicos, em verdade) para se conseguir realizar esses objetivos; só elas, garante o filósofo, permitem que o conhecimento propriamente dito se torne realidade.

\section{A definição de "investigação"}

Existe, segundo Dewey, tanto na investigação do senso comum quanto na científica, um padrão ou estrutura comum, independentemente da natureza dos problemas com que se ocupam os dois modos de pesquisa. A análise que Dewey faz desse padrão comum, que toda investigação humana competente segue, será por nós aqui apresentada, uma vez que tal exame tem o papel de mostrar exatamente como e por que certos meios e instrumentalidades possibilitam não só soluções de problemas, como também os resultados chamados por Dewey de "asserções garantidas" (vale dizer, o próprio conhecimento). Ademais, com esta análise ficará claro que a interação orgânica torna-se investigação quando consequências existenciais são antecipadas, quando condições circundantes são examinadas, e quando atividades de resposta são selecionadas enquanto se enfrenta uma situação de desequilíbrio. Encontraremos as explicações acerca deste padrão comum em Lógica: Teoria da Investigação (1938) e em Como Pensamos (1910). É preciso salientar que, na segunda das obras citadas, Dewey identifica a investigação, ou o ato de solucionar um problema, com a atividade reflexiva, e que tal identificação diz respeito, sobretudo, às finalidades pedagógicas para as quais a obra está voltada. A preocupação maior de Dewey é apresentar neste escrito elementos para se propor a reforma de algumas teorias da educação muito influentes na época em que expôs suas ideias. Assim, o que importa para nós, nesta obra, é somente a estrutura inerente à solução reflexiva de um problema. Como poderemos observar, a estrutura descrita em Como Pensamos contém as mesmas fases que compõem o padrão comum da pesquisa, exposto por Dewey no capítulo VI da Lógica.

Comecemos o assunto assinalando a importância inegável que tem, para o filósofo, a experiência acumulada de investigações realizadas no passado. Para Dewey, é da natureza do método investigativo aperfeiçoar-se. Alguns métodos de agricultura, por exemplo, mostram-se, em determinado momento, desvantajosos em comparação com outros obtidos com base em novas práticas testadas. Se um 
técnico sugere a um lavrador que adote tal ou qual procedimento, está apenas instruindo-o sobre práticas e métodos cuja eficácia tem sido comprovada pela experiência. Métodos há muito utilizados em cirurgia, construção de estradas ou navegação podem a qualquer momento ser substituídos por outros novos comprovadamente mais eficazes, ou seja, melhores. Dewey não quer dizer com isto que estes sejam melhores por serem idealmente perfeitos ou por sua conformidade a alguma forma absoluta. São melhores unicamente porque a experiência assim o mostra. Não obstante, Dewey admite que a abstração desses métodos pode "fornecer uma (relativa) norma ou modelo para novos empreendimentos" (Dewey, 1960, p. 104).

O exame relativo ao modelo ou padrão de investigação é, assim, possível graças ao conhecimento de tipos de investigação que têm e não têm obtido êxito. Dewey acredita que a comparação dos métodos revela como e por que alguns proporcionam asserções garantidas enquanto outros não o fazem, devendo-se este fracasso à incompatibilidade entre meios e consequências.

Podemos já introduzir um momento chave desta nossa análise: a definição de Investigação dada por Dewey. Como poderia ser formulada, de acordo com as ideias de nosso filósofo, uma concepção geral de investigação? Acompanhemos Dewey:

A investigação é a transformação dirigida ou controlada de uma situação indeterminada em uma outra situação de tal modo determinada nas distinções e relações que a constituem, que possa converter os elementos da situação original em um todo unificado (Dewey, 1960, p. 104-5; grifo do autor).

$\mathrm{Na}$ visão do autor, qualquer situação original desordenada está aberta à pesquisa, e isto significa que os constituintes de tal situação não se encontram unidos. Comentaríamos aqui que este é o caso de qualquer situação obscura, ou seja, ainda sem significado, diante da qual perguntamo-nos: o que é a cena que vejo diante de mim? Seus objetos significam ou remetem a quê? Este é, pois, o começo da investigação. Dewey também concebe a situação ordenada não só como o resultado da pesquisa, mas como sinônimo de uma situação fechada ou consumada, ou seja, um todo definido. Para que seja possível a transição de um estado para o outro, o uso do discurso, através dos símbolos, se faz necessário, assim como são necessários também atos ou execuções que comprovam uma solução idealizada. Façamos, neste momento, uma pausa para tecer algumas considerações.

Investigar, para Dewey, não é um ato que deva ser compreendido como procedimento essencialmente teórico, como se todo filósofo devesse apenas refletir sobre alguma questão ou problema, até obter uma explicação racional que sirva como solução. Investigar não envolve somente a capacidade, do cientista como do homem comum, de raciocinar com rigor lógico. Envolve também a experiência concreta de uma situação. Em verdade, a experiência é, garante Dewey, a base de toda investigação. O ato investigativo exige, por conseguinte, para que possa ser levado a cabo, experiência tanto quanto reflexão, ou seja, não apenas a vivência de uma situação como ainda um resultado idealizado ou solução mentalmente antecipada; a investigação é um ato que podemos definir como sendo 
fundamentalmente um agir acompanhado de uma ideia. E é ainda um processo que resulta, no caso da ciência, naquilo que Dewey chama de "conhecimento". Mas qual é exatamente o papel da ideia e da experiência dos fatos na obtenção de tal resultado? A resposta a esta pergunta depende da análise que faremos das etapas da investigação, as quais, na visão de Dewey, compõem seu padrão comum.

Toda investigação ocorre mediante a experiência que tem o organismo humano, em seu meio, de uma situação atualmente desordenada. A natureza mesma de tal situação, segundo Dewey, é ser questionável, uma vez que se mostra atualmente incerta e confusa. Os elementos que compõem a situação confusa são impregnados de uma qualidade peculiar de incerteza única; e é isto o que faz com que a situação que compõem seja precisamente a situação que é: "É esta qualidade única que não apenas evoca a investigação particular envolvida, mas também exerce controle sobre seus procedimentos específicos" (Dewey, 1960, p. 105). Toda situação particular, portanto, possui qualidades únicas, e estas é que determinam o tipo apropriado de investigação a se realizar.

\section{George Berkeley e as raízes imaterialistas da psicologia subjetivista}

Dewey ainda traz inúmeros outros termos que caracterizam uma situação desordenada: esta é confusa, ambígua, cheia de tendências em conflito, etc. Nossos estados pessoais de confusão sempre evocam a experiência concreta de uma situação com as características apontadas. Situações deste tipo não podem ser endireitadas ou ordenadas pela simples manipulação de nossos estados mentais, uma vez que tal tentativa, segundo Dewey, configura patologia. Considerar que a dúvida diz respeito apenas a nós e não a uma situação existencial é, em verdade, herança da psicologia subjetivista a ser evitada. Aqui, Dewey certamente se refere à visão psicológica que, calcada no substrato psíquico, reconhece a primazia do sujeito ou da vida mental sobre o objeto. Diríamos, mais exatamente, que a psicologia subjetivista de que fala nosso autor é a que tem raízes no imaterialismo defendido por George Berkeley, em seu Tratado sobre os Princípios do Conhecimento Humano (1910). Com efeito, para o bispo irlandês, o ponto de partida da capacidade conceptiva é a sensação: "Assim como me é impossível ver ou sentir alguma coisa sem uma sensação atual dessa coisa, assim me é impossível conceber no pensamento uma coisa sensível ou objeto distinto da sensação ou percepção dele" (Berkeley, 1973, p. 20). E um fato óbvio para Berkeley é que, uma vez que todas as percepções ocorrem na mente, a própria existência dos objetos percebidos nunca pode ser concebida como algo independente da mente. Segundo o filósofo, os objetos existem apenas na mente que os percebe, e existem também apenas enquanto são percebidos:

Todo o firmamento e as coisas da terra, numa palavra, todos os corpos de que se compõe a poderosa máquina do mundo não subsistem sem uma mente, de modo que o seu ser é serem percebidos ou conhecidos; consequentemente, enquanto eu ou qualquer outra mente criada não temos deles percepção atual, não têm existência [...]; sendo perfeitamente ininteligível e abrangendo todo o absurdo da abstração atribuir a uma parte deles existência independente da mente. Para ver isto bem claramente, o leitor só 
precisa refletir e tentar separar no pensamento, o ser de um objeto sensível do seu ser percebido (Berkeley, 1973, p. 20; grifo do autor).

Garante ainda o bispo que é impossível conceber os objetos existentes mas não pensados, de modo que "ao esforçarmo-nos ao máximo para conceber a existência de corpos externos, contemplamos sempre e somente as nossas próprias ideias" (Berkeley, 1973, p. 23). Portanto, se não existem objetos externos independentes de nossas sensações, então apenas nossas ideias ou sensações são admitidas. Para Dewey, entretanto, os elementos constituintes do mundo, especialmente nos casos em que constituem uma situação desordenada, não são fatores psicológicos; são, antes, biológicos. Dizem respeito ao estado de desequilíbrio das ações recíprocas entre o organismo e o meio, de sorte que o ordenamento de tal situação depende de operações que modifiquem as condições existenciais.

Uma situação é sempre indeterminada com respeito ao resultado da interação orgânica. Se este resultado não pode ser claramente previsto, então a situação é obscura; é tensa quando são evocadas respostas discordantes do organismo, e assim por diante. Com tais denominações, Dewey quer mostrar que o estado de dúvida não é tão somente um estado mental ou interno; que a investigação nunca tem como alicerce tão somente fatores psíquicos: para o filósofo, o fator orgânico é tão essencial para se apreender uma situação problemática quanto as condições ambientais. Daí é que surgem as respostas adaptativas que dirigirão adequadamente a investigação rumo ao ordenamento da situação.

\section{O padrão da investigação (suas etapas ou fases) e os "fatos do caso"}

A situação indeterminada, portanto, é o momento que antecede toda investigação. Esta última, em si mesma, só tem início com o passo primeiro de se reconhecer a situação como um problema a ser resolvido. Em outros termos, a instituição do problema - garante Dewey - é o degrau inicial da investigação. Antes disso, não há nada de cognitivo na situação indeterminada, embora seja esta a condição necessária para quaisquer operações cognitivas. Qualificar a situação como problemática, no entanto, não nos conduz muito longe. Este ato significa, na investigação, transformar apenas parcialmente uma situação indeterminada em determinada: "É conhecida e significativa a frase segundo a qual um problema bem colocado está semi-resolvido" (Dewey, 1960, p. 108). A função da instituição de um problema é, então, já sugerir, nos termos de seu enunciado, a direção de uma possível solução. Ela já indica a relevância das hipóteses a serem consideradas. Daí Dewey chamar a atenção para uma importante questão: como, afinal, deve ser instituído ou formulado um problema, de modo a encaminhar uma investigação adequada e a consequente solução? Primeiramente, deve-se levar em conta que nenhuma situação que se possa investigar apresenta-se como inteiramente indeterminada, o que permite a seleção de todos os seus dados ou constituintes já conhecidos por experiência, chamados por Dewey de os "fatos do caso". Eles é que já indicam ou sugerem o caminho para uma provável solução.

Em Como Pensamos, evidencia-se a importância de tal observação inicial dos constituintes de uma situação: "As condições que vieram à luz, não importa se por percepção direta ou através da memória, constituem os 'fatos do caso'; são as 
coisas que lá estão, que têm de ser consideradas" (Dewey, 1959, p. 107; grifo do autor). A observação destes fatos e as sugestões desenvolvem-se, assim, em mútua correspondência: "Ao mesmo tempo em que se observam as condições que constituem os fatos a serem tratados, são sugeridos os cursos possíveis de ação" (Dewey, 1959, p. 108).

Dewey, em seguida, afirma que a solução propriamente dita do quadro problemático apresenta-se em forma de hipótese ou ideia (com seus símbolos representativos) enquanto efeito prático antecipado: "Uma ideia é, antes de tudo, uma antecipação de algo que pode ocorrer; caracteriza uma possibilidade" (Dewey, 1960 , p. 109; grifo do autor). A investigação significa a obtenção em etapas da solução de um problema; daí seu caráter progressivo. De início, as ideias que surgem são mais ou menos vagas; em verdade, não são ideias, mas simples sugestões. Estas só se tornam ideias quando examinadas com referência à sua aptidão funcional ou sua capacidade como instrumento de solução do problema em mãos. Este exame, portanto, "corrige, modifica, expande a sugestão original, que passa a constituir, destarte, uma suposição definida, ou, dito mais tecnicamente, uma hipótese" (Dewey, 1959, p. 114; grifo do autor).

$\mathrm{Na}$ investigação, sugestões e ideias referem-se a algo ainda não presente na existência. Isso quer dizer que os significados que envolvem têm que ser incorporados em símbolos, já que não existe ideia sem algum tipo de símbolo. Para Dewey, o suporte de um significado, tanto quanto de um símbolo, é um objeto existente. Assim sendo, "os significados incorporados ou ideias são capazes de inspeção e desenvolvimento objetivos" (Dewey, 1960, p. 110).

Outro procedimento que aparece como fundamental na investigação é o raciocínio. O raciocínio matemático, explica Dewey, opera com base nas abstrações e generalizações feitas a partir da experiência passada com os dados; significa a necessidade de desenvolver os conteúdos das ideias em suas relações recíprocas. Um significado sugerido durante uma pesquisa deve ser examinado em relação a outros significados do sistema do qual participa; a relação em questão constitui uma proposição. Após vários significados intermediários, constrói-se, enfim, para o problema em mãos, um significado mais relevante, que indica ainda a maneira de por à prova sua aplicabilidade: "Em outras palavras, a ideia ou significado, quando desenvolvido no discurso, dirige as atividades que, quando executadas, fornecem o material probatório necessitado" (Dewey, 1960, p. 112).

No caso do raciocínio propriamente científico, uma hipótese ou ideia, depois de sugerida, é desenvolvida juntamente com outras ideias até adquirir uma forma capaz de conduzir um experimento. Este último permite que seja verificada a força operativa da ideia, o que decide se ela deve ser mantida ou descartada. Pode ainda ocorrer de o experimento indicar a necessidade de mudanças na hipótese, para que seja melhorada sua aplicabilidade.

Na última etapa da investigação, Dewey mostra como uma ideia, em especial no âmbito da ciência, converte-se em asserção garantida, ou seja, em conhecimento. Nesta etapa, a ideia deve ser submetida ao teste, devendo-se, assim, observar sua capacidade funcional. Em outros termos, o que se busca é sua confirmação ${ }^{1}$. Para tal, realiza-se, como já dito acima, o experimento, operação em

1 Em Como tornar claras nossas idéias (1858), Peirce, da mesma forma que Dewey, vincula o significado de toda ideia a seus resultados práticos, ou seja, aos fatos, não separando, pois, o pensamento da ação: "Nossa ideia a respeito de algo é nossa ideia acerca de seus efeitos sensíveis" 
que "as condições são deliberadamente arrumadas, de acordo com as exigências de uma ideia ou hipótese, para ver se realmente ocorrem os resultados indicados teoricamente pela ideia" (Dewey, 1959, p. 118).

Foi dito até aqui que, numa situação problemática investigada, os fatos do caso e as construções ideacionais relacionam-se de modo a permitir que se chegue à elaboração de uma possível solução; os fatos do caso são existenciais, enquanto as ideias são não-existenciais. Como é possível, pergunta Dewey, que cooperem na solução de uma situação? Basta, para tal, o reconhecimento de que as ideias são tão operacionais quanto os fatos. As ideias são operacionais porque, como já se sabe, dirigem os experimentos; propõem ações que trazem à existência novos fatos, o que permite, enfim, a organização dos fatos velhos e novos num todo coerente.

Mas e quanto aos fatos? Que significa, questiona Dewey, dizer que são operacionais? Os fatos não são auto-suficientes em si mesmos, ou seja,

[...] são escolhidos e descritos em função de um propósito, a saber, a exposição do problema envolvido, de modo tal que seu material indique um significado relevante para a resolução da dificuldade e sirva para testar seu valor e validade (Dewey, 1960, p. 113).

Os fatos são selecionados de modo a dar-nos maior segurança a respeito de procedimentos a serem postos em prática. Não significam, portanto, algo meramente resultante de simples observações sensoriais. Os fatos escolhidos combinam-se com os já existentes, atendendo a um procedimento de ação já definido; já os que não se adaptam a tal função são deixados de lado. É deste modo que Dewey concebe a operacionalidade dos fatos; eles servem, na investigação, como evidência. Esta, por sua vez, será julgada de acordo com sua capacidade de proporcionar como resultado um todo ordenado. Se os fatos do caso, já conhecidos por experiência passada, fossem completos em si próprios, não desempenhariam papel operativo e nem poderiam servir de evidência.

Os fatos só podem constituir evidência de uma ideia quando estruturados uns com os outros, e isto significa que deve haver interação entre os fatos, sendo a própria investigação composta de uma série de interações. Alguns fatos combinados, explica Dewey, apontam para uma ideia ou solução possível. Esta convida a novas observações. A nova combinação dos fatos resultante modifica a ideia tida no começo. $E$ assim as ideias e observações sucedem-se até que o objetivo da pesquisa seja alcançado; até que a ordem alcançada se mostre unificada e completa.

Ao mesmo tempo, os fatos que vão sendo obtidos por meio dos experimentos que a ideia reguladora sugere são chamados por Dewey de fatos tentativos. Estes

\footnotetext{
(Peirce, 1966, p. 124). E ainda: "Consideremos os efeitos, ou as concebíveis consequências práticas, que pode ter o objeto da nossa concepção. Então, a concepção desses efeitos é toda a nossa concepção do objeto" (Peirce, 1966, p. 124). Para Peirce, conceber uma coisa equivale a conceber como ela funciona ou o que pode realizar, e ainda as ações que suscita de nossa parte. A ideia de "pão", por exemplo, deve não só nos informar de seus possíveis efeitos sobre nosso organismo, como também do modo pelo qual devemos fabricá-lo, manipulá-lo, comê-lo, etc. Neste escrito de Peirce identificamos, assim, uma das marcas de todos os pensadores do pragmatismo: a de que não só a ideia, mas o próprio conhecimento humano devem sempre estar vinculados à ação.
} 
se ligam a técnicas e instrumentos precisos. Por este motivo, não são eles os "fatos do caso", mas são igualmente "testados ou são 'provados' com respeito à sua função probatória, tanto quanto as ideias (hipóteses) são testadas com referência a seu poder no exercício da função de resolução" (Dewey, 1960, p. 114). Portanto, a eficácia operativa dos fatos, tanto quanto das ideias, depende da execução dos experimentos necessários.

Em resumo, a ideia deve operar instituindo, por meio de experimentos, fatos probatórios ainda não observados, e deve também ser utilizada para organizá-los num todo coerente. Assim, enquanto as ideias ou os símbolos logicamente ordenados representam modos de solução, ou possibilidades teóricas para tal, os fatos são elementos presentes existencialmente, prontos a serem escolhidos, estruturados uns com os outros, para que seja possível a formulação de uma solução. E mais: os fatos são a própria consequência prática da inquirição, vindo confirmar, validar e conferir, enfim, sentido à ideia ou solução proposta para o problema. Mas é importante assinalar que, de acordo com Dewey, a confirmação de uma hipótese ou teoria só a torna "certa" para a situação específica atualmente determinada e não para situações posteriores; nestas, a teoria só é válida a título de sugestão ou ideia hipotética. Ela opera, em suma, como instrumento para a ampliação ou continuidade do processo do conhecer, devendo, assim, ser submetida à revisão.

Até aqui, pudemos observar que a investigação se dá, segundo Dewey, em cinco etapas ou momentos fundamentais, constituintes de seu padrão comum. Antes de prosseguirmos, vale a pena recapitularmos brevemente estes passos. Primeiro, deve-se reconhecer uma situação vivenciada como problemática, ou seja, devemos ter conosco a definição precisa da natureza da dificuldade. Esta definição já deve trazer consigo uma sugestão - baseada nos já conhecidos "fatos do caso" - de como resolver o problema. A partir da sugestão, elabora-se uma ideia ou hipótese efetiva de solução, processo este acompanhado de uma discussão raciocinativa para o refinamento da hipótese. Finalmente, o experimento entra em cena para que seja verificada ou confirmada a ideia. Devemos observar, contudo, que, em Como Pensamos, a sequência das cinco etapas não é fixa, ou seja, elas "não se seguem uma à outra em ordem estabelecida" (Dewey, 1959, p. 119). Isso significa, por exemplo, que os passos da sugestão, da formulação da ideia e do raciocínio podem contribuir no sentido de tornar mais completa ou mais precisa e clara a definição do problema, apontada na Lógica como a primeira etapa da pesquisa (ou seja, seu ponto de partida). E quanto mais definido o problema se torna, mais a sugestão é melhorada, o que promove o refinamento da ideia ou hipótese de solução. $O$ processo de aperfeiçoamento de uma ideia também provoca observações que podem fazer surgir novos dados ou fatos, os quais permitem um julgamento mais preciso dos fatos do caso que já se possui. Dewey também não entende que uma hipótese deva surgir só depois que o problema tenha sido definido ou instituído; ela pode aparecer em qualquer dos momentos intermediários. Além disso, "qualquer verificação exterior particular não precisa ser final” (Dewey, 1959, p. 119). A confirmação de uma hipótese pode apenas ser o começo de novas sugestões, caso traga à existência fatos inéditos ou não previstos, que possam revelar mais um aspecto problemático da situação atualmente investigada.

Ainda sobre as cinco fases da investigação, Dewey diz que 
[...] duas delas podem fundir-se, algumas delas podem ser percorridas às pressas, e o esforço de se alcançar uma conclusão pode pesar principalmente numa única fase, que exigirá, então, um desenvolvimento aparentemente desproporcionado (Dewey, 1959, p. 120).

Em verdade, para Dewey não é possível estabelecer regras exatas para o ato investigativo. Sua tentativa de fazê-lo constitui apenas um esboço para uma melhor compreensão dos momentos em que este ato ocorre. De fato, é a peculiaridade do problema presente, assim como a habilidade do indivíduo diante de situações confusas, que determinarão exatamente o número das etapas e a sequência que terão. Ademais, algumas fases podem ampliar-se ou mostrarem-se tão extensas a ponto de conter subfases. Neste caso, "será indiferente considerar as funções como partes ou arrolá-las como fases distintas" (Dewey, 1959, p. 120). Ou seja, o número "cinco", enquanto quantidade de fases da pesquisa, não constitui, de modo algum, uma norma ou princípio definitivamente estabelecido.

Dewey chega até mesmo a admitir, em Como Pensamos, uma sexta fase da investigação, que surge a partir da solução final de uma situação problemática. Para o filósofo, não é raro esta solução significar o registro de um êxito que pode ser traduzido como aquisição de um método confiável para problemas similares no futuro. Em outros termos, a solução "contribui para estabelecer um hábito duradouro de procedimento" (Dewey, 1959, p. 121). O exemplo dado por Dewey é o do médico que, diagnosticando uma doença, elabora uma hipótese sobre como tratá-la. A cura obtida ou a confirmação da hipótese influirá no tratamento de futuros pacientes. Em alguns casos, esta referência ao futuro adquire tamanha importância que requer uma formulação especial, o que faz surgir, portanto, uma etapa adicional da investigação.

\section{As investigações do senso comum e da ciência e uma falha na concepção metodológica de Dewey}

Após o término da discussão acerca do padrão comum da pesquisa, Dewey volta a tecer, na Lógica, considerações a respeito dos fatores que tornam distintos o senso comum e a investigação científica. De fato, já mostramos, em artigo anterior, que a diferença entre os dois modos de inquirição diz respeito, segundo Dewey, mais a seus problemas e objetos específicos do que a suas relações lógicas básicas ${ }^{2}$. Vimos também a diferença existente entre seus respectivos objetivos ou fins. As pesquisas do senso comum lidam com os objetos de uso e desfrute que melhor favorecem a interação orgânica com o meio; seus símbolos e significados estão diretamente conectados com a cultura e os hábitos de um grupo humano. Neste horizonte, somente os objetos do ambiente que são considerados, de acordo com a tradição e os costumes, essenciais para as necessidades da vida pertencem ao sistema de sentidos. De uma perspectiva histórica, antes do surgimento da ciência, não existia, no senso comum, "tal coisa como o ocupar-se intelectual desinteressado com questões físicas" (Dewey, 1960, p. 115). No entanto, já se

\footnotetext{
2 Esta análise foi feita por nós em artigo publicado no ano de 2018, no n. 1 do volume 15 desta revista, com o título John Dewey sobre ciência e senso comum: semelhanças e dessemelhanças.
} 
dispunha de elementos e dados técnicos a partir dos quais a ciência se desenvolveria.

$\mathrm{Na}$ investigação científica, temos os símbolos e significados correlacionados entre si, independentemente de qualquer referência a objetos naturais concretos. Por conseguinte, "uma nova linguagem, um novo sistema de símbolos [...] vem à existência, e em tal nova linguagem a coerência semântica, enquanto tal, é a consideração dominante" (Dewey, 1960, p. 116). Assim, as relações mesmas entre os símbolos tornam-se o objeto da pesquisa científica, ficando as qualidades em segundo plano, ou seja, apenas como auxílio na obtenção das relações. E Dewey não deixa de relembrar que tais relações são instrumentais e não finais em si mesmas.

O que Dewey quer mostrar, em suma, é que, embora os dois tipos de inquirição lidem com finalidades e objetos diferentes, estas diferenças não são incompatíveis com a tese, sustentada pelo próprio Dewey, de que existe um padrão de pesquisa comum a ambos. Naturalmente, as formas lógicas de ambos refletem a mudança dos objetos qualitativos para os não-qualitativos, mas não deixam de estar incluídas nesta estrutura comum que Dewey descreve. Aproveitemos para apresentar uma explicação geral final a respeito do que é comum e do que é próprio a cada uma das investigações. O que há de comum é, pois, a estrutura que acabamos de expor. As etapas desta estrutura verificam-se tanto nas pesquisas do homem comum como nas do cientista. Com respeito às diferenças, temos que os problemas e objetos característicos da ciência mostram-se independentes de qualquer referência ao ambiente enquanto fator de atividades de uso imediato, enquanto os problemas e objetos do senso comum possuem referência direta às condições do meio. Na ciência, as combinações entre conceitos ou símbolos, assim como as conclusões daí resultantes, estão livres de restrições a condições referentes a tempos e lugares específicos, o que significa que sua aplicação se dá a qualquer conjunto de condições existenciais que preencham as relações gerais especificadas nos conceitos científicos, ao passo que as generalizações e conclusões do senso comum restringem-se às experiências e interações concretas, bem como aos símbolos estabelecidos a partir da cultura habitual de um determinado grupo. Enfim, na ciência, o objetivo é conhecer as propriedades fundamentais constitutivas dos objetos com a preocupação maior de realizar experimentações e confirmar teorias científicas, enquanto no senso comum buscase apenas conhecer o modo como os objetos podem ser utilizados na satisfação de necessidades corriqueiras e comuns, individuais ou coletivas.

Nosso filósofo faz questão ainda de sublinhar um aspecto particularmente importante da investigação transformadora do meio: o fato de ser ela um procedimento existencial, e, portanto, temporal. Uma situação indefinida só pode ser definida com a modificação de seus elementos constituintes, proporcionada pelas operações experimentais. O raciocínio, por seu turno, entra em cena como um guia nestas operações. Ora, de vez que este mesmo princípio se relaciona com as ciências da natureza, a reordenação dos elementos situacionais por meio dos experimentos que estas ciências efetuam constitui, para Dewey,

[...] evidência adicional da unidade do padrão da investigação. A qualidade temporal da investigação significa, portanto, algo totalmente diverso de que o processo da investigação toma tempo. 
Significa que o objeto da investigação sofre modificação temporal (Dewey, 1960, p. 118).

Comentaríamos que esta modificação temporal de que fala Dewey significa sobretudo uma reestruturação efetiva das condições circundantes, que só é realizada com a execução passo-a-passo dos procedimentos contidos no padrão da investigação. Seu sentido, portanto, não é simplesmente a necessidade de se "gastar certo tempo" com cada uma das etapas da investigação.

Podemos agora, uma vez concluída a exposição das fases que compõem o padrão da investigação, encerrar este documento apresentando algumas críticas, feitas por Kaufmann (1959), ao modo como Dewey concebe, na Lógica, a relação entre a metodologia e a lógica da pesquisa. Já conhecemos a tese de Dewey segundo a qual a lógica é assunto estreitamente dependente do ato investigativo ${ }^{3}$. Kaufmann, no entanto, apresenta alguns questionamentos que parecem limitar a validade deste ponto de vista. Lembra o comentador que, na visão de Dewey, a transformação de uma situação indeterminada em determinada é realizada por uma série de passos em conformidade com dadas regras de procedimento, sendo estes passos e regras os componentes do padrão da investigação, como acabamos de constatar. As regras são postulados que permitem avaliações críticas de cada passo. Mas entende Kaufmann que a lógica aí envolvida não é em absoluto um assunto relacionado com a sequência temporal dos passos, enquanto temporal, mas apenas com a estrutura formal desta sequência. Para ele, "a 'dependência' dos passos subsequentes em relação aos precedentes é, deste ponto de vista, não uma dependência causal, mas lógica" (Kaufmann, 1959, p. 833). Kaufmann utiliza uma analogia com um processo de cálculo aritmético para elucidar o ponto: pode-se, segundo ele, admitir

[...] que a designação do número 5 a um objeto ocorre depois da designação do número 2 , ou que a prévia designação do número 2 é uma condição necessária para a designação do número 5 . Mas a correspondente proposição matemática '5 implica 2' não possui qualquer referência ao tempo ou à causalidade (Kaufmann, 1959, p. 833).

Kaufmann admite que, na descrição da investigação como uma atividade humana com um propósito, podemos propriamente falar da contribuição de cada passo na investigação para a solução do problema dado, e da funcional (ou operacional) interdependência dos diferentes passos. Mas tais termos não têm lugar, defende ele, em uma análise da estrutura formal da investigação, a qual é um procedimento caracteristicamente lógico.

O comentador insiste ainda uma vez em que o caráter lógico da investigação de que fala Dewey não está relacionado com o processo de investigação enquanto processo temporal, mas apenas com sua estrutura formal; ou seja, com os diferentes tipos de cânones metodológicos e suas interrelações. Os critérios para

\footnotetext{
${ }^{3}$ Conforme mostramos em artigo publicado no ano de 2014, no n. 2 do volume 11 desta revista, com o título A teoria da investigação de John Dewey: lógica e conhecimento.
} 
distinguir entre métodos que têm sucesso e métodos que fracassam na investigação devem ser estabelecidos dentro deste sistema lógico de regras ligadas à investigação. De outra forma, conclui o comentador, "não se tem um procedimento científico autônomo" (Kaufmann, 1959, p. 834).

\section{Conclusão}

O padrão comum de toda investigação competente indica que é da natureza de todo método de pesquisa aperfeiçoar-se, e que tal aperfeiçoamento inclui a revisão de conceitos e teorias sempre que os dados obtidos assim o exigem. Para Dewey, nenhuma investigação ocorre sem que se tenha primeiramente a experiência de uma situação atualmente desordenada. A investigação é, portanto, uma operação existencial; ela tem como objetivo modificar a situação conflituosa previamente existente, o que a vincula a um quadro de interação orgânica, e não à estrutura última de uma "Realidade" transcendente. Para Dewey, os elementos conceituais, tanto quanto os perceptivos, aparecem correlacionados nas etapas da pesquisa, de forma que os primeiros são vistos sempre como uma solução possível para o problema concreto vivenciado, enquanto os segundos significam a localização e a descrição do problema. Ambos são estabelecidos na e pela investigação em curso, e são validados unicamente com base em sua capacidade de trabalhar em conjunto a fim de proporcionar, ao final, uma situação unificada, harmoniosa, ou seja, solucionada. Neste contexto, a solução do quadro problemático apresenta-se sempre em forma de hipótese ou ideia enquanto efeito prático antecipado. Ela deve ser, então, examinada com referência à sua capacidade como instrumento de solução do problema. Este exame da ideia é o raciocínio, o qual opera com base nas abstrações e generalizações feitas a partir da experiência passada com os dados. Nesta fase, desenvolvem-se os conteúdos das ideias em suas relações recíprocas, o que permite a geração de proposições e, com elas, a obtenção de um significado mais relevante para o problema.

A ideia só poderá chegar, enfim, ao grau de conhecimento quando submetida ao teste; deve-se obter, assim, sua confirmação. A idéia é aquilo que, segundo Dewey, institui, por meio de experimentos, fatos probatórios ainda não observados, e deve também ser utilizada para organizá-los num todo coerente. Assim, os fatos são a própria consequência prática da inquirição, vindo confirmar, validar e conferir, enfim, sentido à teoria ou solução proposta para o problema.

\section{REFERÊNCIAS:}

BERKELEY, G., Tratado sobre os Princípios do Conhecimento Humano. Col. Os Pensadores, v. 23. São Paulo: Abril Cultural, 1973.

CABRAL, C. A teoria da investigação de John Dewey: lógica e conhecimento. Cognitio-Estudos: revista eletrônica de filosofia. São Paulo: V. 11, n. 2, 2014. 
John Dewey sobre ciência e senso comum: semelhanças e dessemelhanças. Cognitio-Estudos: revista eletrônica de filosofia. São Paulo: V. 15, n. 1, 2018.

DEWEY, J. Como Pensamos. São Paulo: Companhia Editora Nacional, 1959.

1960.

Logic: The Theory of Inquiry. New York: Holt, Rinehart and Winston, Cultural, 1974.

Textos Selecionados. Col. Os Pensadores, v. 40. São Paulo: Abril

KAUFMANN, F. John Dewey's Theory of Inquiry. The Journal of Philosophy, v.56, n.21, 1959.

PEIRCE, C. S. Selected Writings. New York: Dover Publications, 1966.

. Como tornar claras as nossas ideias. Semiótica e Filosofia. 2. edição. São Paulo: Editora Cultrix; Editora da USP, 1975.

. Como tornar claras nossas ideias. Ilustrações da Lógica da Ciência. Aparecida, SP: Ideias \& Letras, 2008. 